\title{
PENGENALAN TEKNOLOGI GLOBAL POSITIONING SYSTEM (GPS) SEBAGAI ALAT BANTU OPERASI PENANGKAPAN IKAN DI PANGANDARAN
}

\author{
Izza M Apriliani' ${ }^{1}$, Heti Herawati², Alexander M Khan' ${ }^{1}$, Lantun P Dewanti ${ }^{1}$, A Rizal ${ }^{3}$ \\ ${ }^{1}$ Laboratorium Teknologi dan Manajemen Perikanan Tangkap, FPIK Universitas Padjadjaran \\ ${ }^{2}$ Laboratorium Manajemen Sumberdaya Perairan, FPIK Universitas Padjadjaran \\ ${ }^{3}$ Pusat Studi Sosial Ekonomi Perikanan, FPIK Universitas Padjadjaran \\ E-mail: izza.mahdiana@unpad.ac.id
}

\begin{abstract}
ABSTRAK. Letak Pangandaran yang berhadapan dengan Samudera Hindia membuat sebagian penduduknya bermata pencaharian sebagai nelayan dengan peralatan menangkap ikan yang sederhana. Teknologi Global Positioning System (GPS) ini diharapkan mampu meningkatkan kualitas dan kuantitas tangkapan nelayan yang dapat menaikkan pendapatan dan kesejahteraan kehidupan nelayan. Pembekalan teknologi GPS diharapkan dapat meningkatkan pengetahuan nelayan akan pentingnya penggunaan alat bantu GPS dalam mendukung efektivitas penangkapan ikan. Berdasarkan hasil kegiatan pelatihan/workshop penggunaan GPS dalam operasi penangkapan ikan di Kab. Pangandaran perlu dilakukan keberlanjutan program. Keterampilan peserta pelatihan dalam pengoperasian GPS dapat dikatakan meningkat secara signifikan. Buktinya dapat terlihat dari nelayan dapat mengoperasikan GPS dengan baik sehingga dapat diaplikasikan dalam kegiatan penangkapan ikan. Keberlanjutan program yang patut untuk dipertimbangkan adalah pengajuan bantuan GPS pada nelayan skala kecil ini. Sehingga nelayan skala kecil tersebut dapat meningkatkan produktivitasnya dan memberikan sumbangsih pada perikanan tangkap di Indonesia.
\end{abstract}

Kata kunci: GPS; penangkapan; Pangandaran

\begin{abstract}
The location of Pangandaran in dealing with the Indian Ocean makes a part of its population work as fishermen with simple fishing equipment. The Global Positioning System (GPS) technology is supposed to improve the quality and quantity of fishermen's catches that can increase the income and welfare of fishermen's lives. Providing GPS technology is expected to increase fishermen's knowledge of the importance of using GPS tools in supporting the effectiveness of fishing. Build on the results of training activities / workshops on the use of GPS in fishing operations in Kab. Pangandaran has to be continued in the program. The skills of trainees in the operation of GPS can be reported to increase significantly. The proof can be seen from fishermen being able to operate GPS properly so that it can be implemented in fishing activities. The sustainability of the program that deserves consideration is the submission of GPS assistance to these small-scale fishermen. So that small-scale fishermen can increase their productivity and contribute to capture fisheries in Indonesia.
\end{abstract}

Key words: Global Positioning System; fishing; Pangandaran

\section{PENDAHULUAN}

Pangandaran merupakan salah satu kabupaten di Provinsi Jawa Barat. Kabupaten ini berbatasan dengan Kabupaten Ciamis dan Kota Banjar di utara, Kabupaten Cilacap di timur, Kabupaten Tasikmalaya di barat, dan Samudera Hindia di selatan. Pangandaran dengan pantainya yang terlindungi karena terdapat sebuah daratan yang menjorok ke laut dan sekarang menjadi cagar alam atau hutan lindung. Tanjung inilah yang menghambat atau menghalangi gelombang besar untuk sampai ke pantai sehingga menyebabkan gelombang laut yang kecil yang memudahkan mencari ikan dan menyimpan perahu.

Letak Pangandaran yang berhadapan dengan Samudera Hindia membuat sebagian penduduknya bermata pencaharian sebagai nelayan dengan peralatan menangkap ikan yang tradisional. Berdasarkan kondisi yang demikian, untuk meningkatkan kualitas dan kuantitas hasil tangkapan maka diperlukan suatu pengenalan terhadap masyarakat nelayan di Pangandaran tentang teknologi alat penangkap ikan berupa Global Positioning System (GPS).

GPS adalah sistem satelit navigasi dan penentu posisi yang memberikan posisi dan kecepatan tiga dimensi dan informasi waktu, secara kontinyu di seluruh dunia tanpa tergantung kepada waktu dan cuaca (Abidin dkk., 2009). GPS merupakan suatu alat yang dapat digunakan oleh para nelayan untuk menandai lokasi dimana ikan-ikan sering berkumpul sehingga dapat diketahui pola sebaran ikan yang teratur. Fungsi lainnya dapat mengetahui munculnya ikan di suatu perairan yang dapat digunakan untuk mengetahui lokasi yang tepat di kemudian hari. Teknologi GPS ini diharapkan mampu meningkatkan kualitas dan kuantitas tangkapan nelayan yang dapat menaikkan pendapatan dan kesejahteraan kehidupan nelayan.

Kegiatan operasi penangkapan ikan oleh nelayan di Pangandaran tidak menggunakan alat bantu navigasi di kapalnya. Nelayan pada umumnya memiliki GPS yang merupakan bantuan pemerintah, namun tidak dapat mengoperasikannya dikarenakan minimnya pengetahuan dalam mengoperasikan alat GPS tersebut. Dengan deminikian perlu adanya sosialisasi penggunaan GPS dalam pendugaan fishing ground dalam rangka mendukung keberhasilan operasi penangkapan ikan di Pangandaran.

\section{METODE}

Kegiatan Pelatihan / Work-Shop Training of Trainer (TOT) dilakukan dalam beberapa bentuk kegiatan yaitu pemberian dan pengayaan materi, demonstrasi partisipatif, dan pembuatan media untuk materi penyuluhan (Hidayat dkk., 2016). Khalayak sasaran dari kegiatan ini adalah 
kelompok nelayan dari seluruh wilayah di Kabupaten pangandaran. Nelayan akan diberikan pengetahuan dengan cara penyuluhan tentang pentingnya mengetahui adanya teknologi GPS, pentingnya penggunaan GPS dalam operasi penangkapan ikan serta kemudahan GPS dalam meningkatkan produktivitas nelayan. Dilanjutkan dengan pelatihan dan demonstrasi penggunaan GPS. Kegiatan ini merupakan kegiatan belajar sambil bekerja atau mempraktekkannya (learning by doing). Hasil dari kegiatan ini adalah membawa perubahan dalam hal pengetahuan (knowledge), cara berfikir (thinking), kecakapan (skill) dan sikap.

\section{HASIL DAN PEMBAHASAN}

Fungsi pokok GPS adalah untuk menentukan posisi lintang dan bujur kapal, kecepatan kapal, jarak tempuh kapal, memperkirakan jarak waktu datang di pelabuhan tujuan, sisa waktu tempuh, menyimpan posisi kapal yang diinginkan, menentukan jejak pelayaran dalam bentuk peta, dan membuat bagan panduan bernavigasi (Moeshariyanto dan Saputra, 2009). Dengan demikian, GPS sangat penting digunakan sebagai alat bantu navigasi kegiatan penangkapan ikan. Pemasangan GPS pada kapal penangkapan dapat diintegrasikan pada Echosounder atau Fish Finder untuk menentukan posisi fishing ground dengan tepat. Selain itu penggunaan GPS dapat berupa penyimpanan koordinat lokasi sehingga bisa ditemukan dengan mudah di kemudian hari.

Perkembangan teknologi GPS ini seharusnya dapat dirasakan oleh nelayan dalam kegiatan operasi penangkapan ikan. Perairan Pangandaranmempunyai potensi sumberdaya hayati laut yang cukup besar (Nurhayati, 2013). Kondisi perairan yang berhubungan langsung dengan Samudera Hindia mempengaruhi karakteristik oseanik perairan tersebut. Potensi sumberdaya ikan laut yang terdapat di perairan Pangandaran seharusnya dapat dimanfaatkan secara optimal.

Wilayah yang memiliki aktivitas perikanan tangkap yang padat di Kabupaten Pangandaran akan menjadi sasaran utama pelaksanaan kegiatan tersebut. Rekomendasi oleh Dinas Kelautan, Perikanan dan Ketahanan Pangan Kabupaten Pangandaran bahwa disarankan untuk melibatkan perwakilan dari setiap wilayah pangkalan pendaratan ikan. Sehingga diharapkan dapat mewakili seluruh nelayan yang ada di Kabupaten Pangandaran. Hal ini disebabkan oleh seiring meningkatnya perkem-bangan teknologi yang mengharuskan nelayan dapat meningkatkan softskill untuk meningkatkan produk-tivitasnya. Solusi alternatif yang dilaksanakan adalah fokus terhadap perwakilan-perwakilan Rukun Nelayan yang hadir agar memiliki pengetahuan mengenai GPS dan dapat disalurkan kepada nelayan di wilayahnya.

Tahapan kegiatan dilakukan dalam 3 (tiga) tahap yaitu tahap sosialisasi dan inisiasi, tahap penyuluhan dan pelatihan serta tahap evaluasi dan monitoring kegiatan. Secara lengkap, tahapan kegiatan disajikan dalam Tabel 1.
Tabel 1. Tahapan kegiatan sosialisasi GPS

\begin{tabular}{llcc}
\hline \multirow{2}{*}{ No. } & \multicolumn{2}{c}{ Tahapan Kegiatan } & \multicolumn{2}{c}{ Keterlibatan dalam kegiatan } \\
\cline { 3 - 4 } & & Penyelenggara & $\begin{array}{c}\text { Khalayak } \\
\text { Sasaran }\end{array}$ \\
\hline 1. & $\begin{array}{l}\text { Tahap sosialisasi dan } \\
\text { inisiasi }\end{array}$ & $\mathrm{v}$ & \\
2. & $\begin{array}{l}\text { Tahap penyuluhan dan } \\
\text { pelatihan, terkait : } \\
\text { a) Pentingnya GPS dalam } \\
\text { operasi penangkapan }\end{array}$ & $\mathrm{v}$ & $\mathrm{V}$ \\
$\quad \begin{array}{l}\text { ikan; } \\
\text { b) Pelatihan dan demonstrasi } \\
\text { penggunaan GPS dalam } \\
\text { peningkatan produktivitas } \\
\text { penangkapan ikan. }\end{array}$ & $\mathrm{V}$ & $\mathrm{V}$ \\
\hline $\begin{array}{l}\text { Tahap Evaluasi dan } \\
\text { Monitoring kegiatan }\end{array}$ & $\mathrm{v}$ & \\
\hline
\end{tabular}

\section{Penyuluhan Pentingnya GPS dalam Kegiatan Penangkapan Ikan}

Pelatihan merupakan proses introduksi pengetahuan dari pemberi ceramah kepada khalayak sasaran. Pengetahuan yang disampaikan dalam kasus ini adalah pentingnya GPS dalam kegiatan penangkapan ikan. Pemberi materi adalah Dosen dari Fakultas Perikanan dan Ilmu Kelautan Universitas Padjadjaran. Khalayak sasarannya adalah nelayan Kabupaten Pangandaran.

Kegiatan sosialisasi bertempat di Tempat Pendaratan Ikan Nusawiru. Kegiatan sosialisasi berlangsung selama 1 jam, dimulai dari pukul 13.00 sampai dengan 14.00 WIB. Peserta yang mengikuti kegiatan ini sebanyak 40 orang.

Suasana penyampaian materi berlangsung dalam suasana keakraban dan kekeluargaan. Bahasa yang digunakan oleh pemateri adalah campuran antara bahasa Sunda dan bahasa Indonesia. Penggunaan kedua bahasa ini dimaksudkan agar pesan yang hendak disampaikan efektif dan efisien. Peserta sangat antusias dalam menyimak dan mendengarkan materi yang disampaikan oleh pemberi materi. Suasana keakraban tetap terjaga selama penyampaian materi tersebut berlangsung.

Akhir dari kegiatan penyampaian materi adalah diskusi. Diskusi dimaksudkan untuk lebih mempertajam pesan yang telah disampaikan saat ceramah. Berbagai pertanyaan dan pendapat dilontarkan oleh para peserta sehingga suasana pertemuan terasa akrab dengan semangat kekeluargaan. Banyaknya pertanyaan dan lontaran pendapat tersebut menunjukkan bahwa materi yang disampaikan dapat dikatakan telah tersampaikan kepada objek sasasaran dengan baik. Beberapa faktor yang mempengaruhi keberhasilan ini antara lain tingkat pendidikan objek sasaran. Para peserta berpendidikan SLTA, dan ada juga yang lulusan paket C. Selain itu pendukung lainnya adalah keinginan peserta yang sangat kuat untuk menerima materi yang disampaikan oleh tim. Semangat dari khalayak sasaran ini merupakan modal utama yang harus tetap terjaga agar supaya kegiatankegiatan berikutnya dapat berjalan dengan baik dan mendapatkan hasil yang optimal.

Fakta yang sangat menarik dalam diskusi tersebut 
Tabel 2. Indikator pelaksanaan program

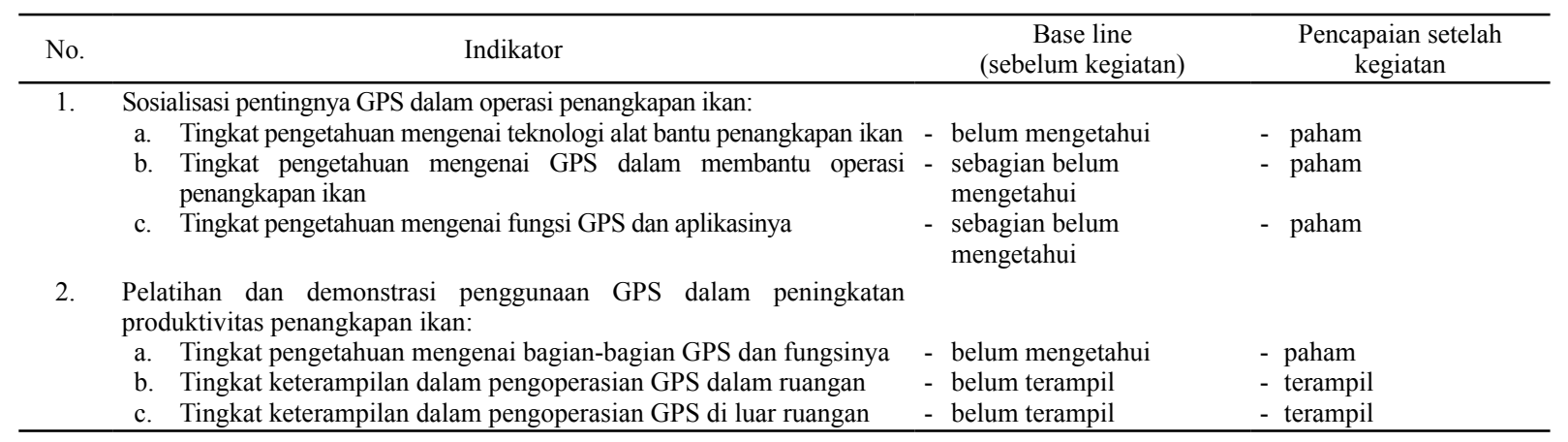

adalah pemberi materi menempatkan dirinya sebagai bagian dari kelompok masyarakat sehingga para peserta menjadi terbuka dalam mengemukakan permasalahan dan pandangannya. Menurut Adimihardja dan Hikmat (2004), teknik penyampaian tersebut merupakan salah satu metode Participatory Research Apprasial. Dalam hal ini, pemateri berusaha menempatkan posisi sebagai insider. Pada akhir diskusi, umumnya para peserta menyadari dan memahami tentang pentingnya GPS dalam mendukung operasi penangkapan ikan.

\section{Pelatihan Penggunaan GPS}

Kegiatan pelatihan atau workshop penggunaan GPS dengan membagi peserta menjadi 5 kelompok yang berisi 8 orang nelayan. Setiap kelompok didampingi oleh 1 tim penyuluh yang mengarahkan penggunaan GPS. Setiap nelayan wajib menggunakan GPS pada saat marking hingga menuju waypoint yang telah disediakan oleh pemateri. Hal ini efektif untuk meningkatkan skill nelayan dalam mengoperasikan GPS. Kendala yang terjadi selama pelatihan secara umum adalah nelayan masih ragu-ragu dalam mengoperasikan GPS.

Kegiatan pelatihan ini dapat memberikan wawasan baru terhadap nelayan. Nelayan terlihat antusias dalam menerima materi dan dapat mengikuti selama aplikasi penggunaan GPS di lapangan. Selain itu nelayan sangat aktif untuk menanyakan terkait kendala-kendala teknis yang terjadi pada saat pengoperasian GPS.

Kegiatan pembekalan mengenai teknologi GPS kepada nelayan secara umum telah berjalan sesuai dengan harapan. Hal tersebut dituangkan dalam indikator yang dapat dilihat pada Tabel 2. Nelayan pada umumnya mengetahui GPS namun pada kenyataannya belum pernah melihat alat tersebut secara langsung. Nelayan berpengalaman mengikuti kapal peangkapan ikan skala besar secara umum sudah mengetahui kegunaan GPS. Dengan demikian, melalui kegiatan ini semua nelayan mampu dalam mengoperasikan GPS dalam mendukung operasi penangkapan ikan. Kelemahannya hanya daya beli nelayan dalam memenuhi alat GPS tersebut.

\section{SIMPULAN}

Berdasarkan hasil kegiatan pelatihan/workshop penggunaan GPS dalam operasi penangkapan ikan di Kab.
Pangandaran bahwa keterampilan peserta pelatihan dalam pengoperasian GPS dapat dikatakan meningkat secara signifikan. Buktinya dapat terlihat dari nelayan dapat mengoperasikan GPS dengan baik sehingga dapat diaplikasikan dalam kegiatan penangkapan ikan. Keberlanjutan program yang patut untuk dipertimbangkan adalah pengajuan bantuan GPS pada nelayan skala kecil ini. Sehingga nelayan skala kecil tersebut dapat meningkatkan produktivitasnya dan memberikan sumbangsih pada perikanan tangkap di Indonesia.

\section{UCAPAN TERIMAKASIH}

Penulis mengucapkan terima kasih kepada Direktorat Riset, Pengabdian Pada Masyarakat dan Inovasi Universitas Padjadjaran yang telah memberikan dana hibah Pengabdian Pada Masyarakat tahun anggaran 2018. Ucapan terima kasih disampaikan kepada Dinas Kelautan, Perikanan dan Ketahanan Pangan Kabupaten Pangandaran dan perwakilan Rukun Nelayan yang telah hadir sehingga program pengabdian ini dapat terlaksana dengan baik.

\section{DAFTAR PUSTAKA}

Abidin, H.Z., Andreas, H. Meilano, I., Gamal, M., Gumilar, I., dan Abdullah, C.I. 2009. Deformasi Koseismik dan Pascaseismik Gempa Yogyakarta 2006 dari Hasil Survei GPS. Jurnal Geologi Indonesia. 4 (4): 275-284.

Adimiharja, A., dan Hikmat, H. 2004. Participatory Research Apprasial. Bandung: Humaniora Utama Press.

Hidayat, W., Nuraeni, N., dan Wahyuni, I.S. 2016. Pembekalan Pengetahuan dan Kemandirian dalam Perawatan Kesehatan Gigi dan Mulut Masyarakat Desa Balingbing dan Desa Cidadap, Kecamatan Pagaden Barat, Subang. Dharmakarya. 5 (1): 3437.

Moeshariyanto, G., dan Saputra, C. 2009. Navigasi Radar Navigasi Elektronik. Banyuwangi : Balai Pendidikan dan Pelatihan Perikanan Banyuwangi.

Nurhayati, A. 2013. Analisis Potensi Lestari Perikanan Tangkap di Kawasan Pangandaran. Jurnal Akuatika. 4(2): 195-209. 